\title{
Structural Determination of 4-Vinylcyclohexene Oxide Using 2D INADEQUATE NMR Spectroscopy and MNDO Calculation
}

\author{
Atsushi Udagawa, Yasuhiko Yamamoto, Yoshio Inoue, \\ and Riichirô CHûjô \\ Department of Biomolecular Engineering, Tokyo Institute of Technology, 12-1, \\ O-Okayama 2-chome, Meguro-ku, Tokyo 152, Japan
}

(Received February 5, 1990)

\begin{abstract}
The stereochemical structure of the cycloaliphatic epoxy monomer, 4vinylcyclohexene oxide (VCO), was determined using ${ }^{13} \mathrm{C}$ NMR spectroscopy and quantum chemical calculation. The ${ }^{13} \mathrm{C} 2 \mathrm{D}$ INADEQUATE NMR spectrum of VCO showed that this compound is composed of 4 stereochemical isomers. Although NMR spectroscopy is unavailable to identify the structure of the isomers, the isomeric energy calculations using the MNDO method lead to the complete structural determination of them. Among 8 isomers in terms of the bond connecting cyclohexene oxide ring and ethylene oxide ring, the equatorial forms were considerably more stable than the axial forms. Thus the former were isomers found in the ${ }^{13} \mathrm{C}$ NMR spectrum of VCO. In addition, the isomeric composition was obtained from the signal intensity of the NOE-suppressed ${ }^{13} \mathrm{C}$ NMR spectrum.

KEY WORDS $\quad{ }^{13} \mathrm{C}$ NMR / 2D-INADEQUATE NMR / MNDO / Epoxy Resin / Molecular Structure /
\end{abstract}

Epoxy resins are compounds which possess more than two oxirane rings in the molecule. By reaction with curing agents, they form three-dimensional network structures. The properties of the cured epoxy resins largely depend on the structures of the starting resins and hence NMR spectroscopy has been widely utilized for the characterization of epoxy resins. ${ }^{1-8}$ In addition, the recent development of two-dimensional (2D) NMR spectroscopy has enabled the complete spectral assignments of epoxy resins. ${ }^{5-8}$

We recently determined the stereochemical structure of two cycloaliphatic epoxy resins, 3,4-epoxycyclohexylmethyl-3',4'-epoxycyclohexene carboxylate (ECC) and 3,4-epoxycyclohexyladipate (EA), by ${ }^{1} \mathrm{H}$ and ${ }^{13} \mathrm{C}$ NMR spectroscopies. ${ }^{8}$ Cycloaliphatic epoxy resins are compounds which contain the ring structure of cyclohexene oxide in the molecule.
The molecular structure of cyclohexene oxide is a sort of deformed "staircase", 9 and resembles that of cyclohexene rather than that of cyclohexane. The four carbon atoms nearest to the oxygen atom are coplanar, and two remaining carbons are placed one above and the other below this plane in the cyclohexene oxide molecule. We previously found that ECC and EA are mixtures of 3 and 4 stereochemical isomers, respectively, due to this distorted ring structure. $^{8}$ 2D INADEQUATE (incredible natural abundance double quantum experiment) technique, ${ }^{10-14}$ which has been developed as a reliable method to determine the connectivity of carbon atoms, was demonstrated to be a useful method for the ${ }^{13} \mathrm{C} \mathrm{NMR}$ signal assignments of a mixture of some isomers.

In this paper 4-vinycyclohexene oxide (VCO), which is a typical source of cycloali- 
phatic epoxy resin, was investigated by ${ }^{13} \mathrm{C}$ NMR spectroscopy. The ${ }^{13} \mathrm{C}$ NMR signal assignments of VCO were carried out using 2D INADEQUATE technique. The obtained assignments revealed the existence of 4 stereochemical isomers in this epoxy resin. The isomeric composition was obtained from the signal intensity of the nuclear Overhauser effect (NOE)-suppressed ${ }^{1} \mathrm{H}$-decoupled ${ }^{13} \mathrm{C}$ NMR spectrum $^{1}$ measured under the conditions sufficient to quantitative analysis. Furthermore, the stereochemical structure of these isomers was determined by semi-empirical quantum chemical calculations using the modified neglect of diatomic overlap (MNDO) method. ${ }^{15}$

\section{EXPERIMENTAL}

\section{Materials}

4-Vinylcyclohexene oxide (VCO) was purchased from Union Carbide and used without further purification. The structural formula of $\mathrm{VCO}$ is given in the inset of Figure 1. The sample was dissolved in $\mathrm{CDCl}_{3}$ with a concentration of $50 \%$ by weight for the NMR measurements.

\section{NMR Measurements}

The ${ }^{1} \mathrm{H}$-decoupled ${ }^{13} \mathrm{C}$ NMR spectra were recorded on a JEOL GSX-500 spectrometer operated at a ${ }^{13} \mathrm{C}$ frequency of $125 \mathrm{MHz}$. Typical spectra were collected with $4 \mathrm{~s}$ pulse repetition, $9000 \mathrm{~Hz}$ spectral width, $32 \mathrm{~K}$ data points, and 64 accumulations. The NOEsuppressed ${ }^{1} \mathrm{H}$-decoupled ${ }^{13} \mathrm{C}$ NMR spectra were recorded with $9000 \mathrm{~Hz}$ spectral width, $32 \mathrm{~K}$ data points, and 2500 accumulations. The pulse duration time was set to at least 10 times of the longest spin-lattice relaxation time of the sample and was typically $20 \mathrm{~s}$.

2D INADEQUATE experiments were carried out using the sequence of $90^{\circ}-T-180^{\circ}-T$ $90^{\circ}-t_{1}-135^{\circ}-t_{2}$ (acq). The delay time $T$ was set to $7.14 \mathrm{~ms}$, where $T=\left(4 J_{\mathrm{CC}}\right)^{-1}$ and $J_{\mathrm{CC}}=35$ Hz. A total of 256 transients was accumulat- ed per $\tau$ value with a pulse delay of $2 \mathrm{~s}$. The initial data set consisted of a $2048 \times 128$ matrix with $9000 \mathrm{~Hz} \times 18000 \mathrm{~Hz}$ spectral widths, and was expanded to the final matrix size, $4096 \times 256$, by zero filling.

All NMR measurements were carried out at $40^{\circ} \mathrm{C}$. Chemical shifts are given in parts per million (ppm) from tetramethylsilane with $\mathrm{CDCl}_{3}$ as internal reference $(77.0 \mathrm{ppm})$.

\section{MNDO Calculations}

Isomeric energy calculations of VCO were performed on a SUN-4 minicomputer system using the MNDO method. ${ }^{15,16}$ The atomic coordinates of a VCO molecule were obtained from the coordinates of cyclohexene oxide ${ }^{9}$ and ethylene oxide. ${ }^{17}$ The energies of some conformers arising from the $\mathrm{C}_{1}-\mathrm{C}_{7}$ conformation were calculated for each model, and the lowest value among the conformers was adopted for the isomeric energy.

\section{RESULTS AND DISCUSSION}

${ }^{13}$ C NMR Signal Assignments of 4-Vinylcyclohexene Oxide

The ${ }^{13} \mathrm{C}$ NMR spectrum of 4-vinylcyclohexene oxide (VCO) is shown in Figure 1. There are 8 chemically different carbons in the VCO molecule as seen from the structural formula in Figure 1. There are, however, 32 resonances observed in the ${ }^{13} \mathrm{C} \mathrm{NMR}$ spectrum, suggesting that VCO consists of the mixture of 4 isomers.

In Figure 2 is shown the 2D INADEQUATE spectrum of VCO. The abscissa and ordinate represent the usual chemical shifts and double quantum frequencies, respectively. One set of ${ }^{13} \mathrm{C}-{ }^{13} \mathrm{C}$ connectivities which trace out along the carbon skeleton of VCO is indicated by solid line in the spectrum. In all, four independent ${ }^{13} \mathrm{C}-{ }^{13} \mathrm{C}$ connectivities are clearly observed, indicating the existence of 4 isomers (Isomers $\mathrm{A}-\mathrm{D}$ ). The assignments are summarized in Table I.

The composition ratios of the VCO isomers were calculated from their $\mathrm{C}_{1}$ signal (chemical 


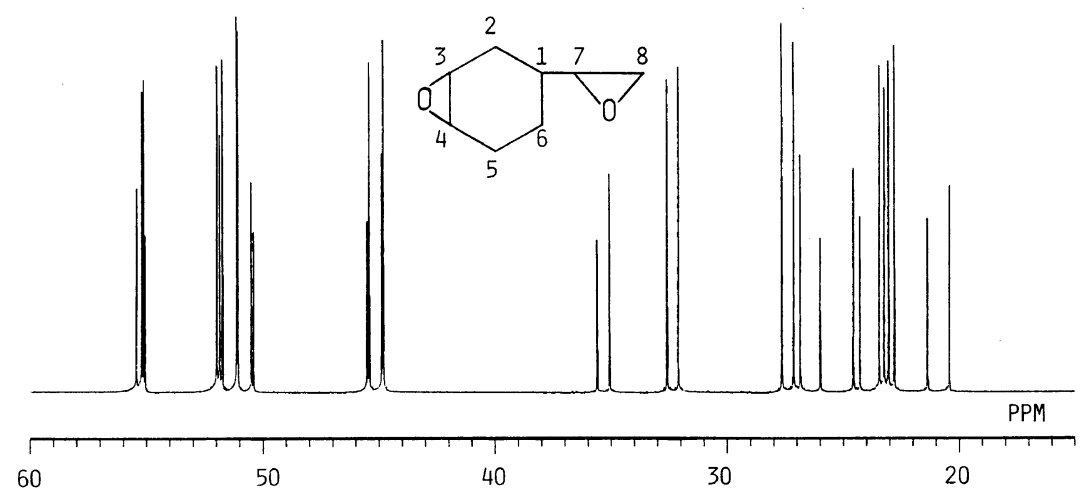

Figure 1. $125 \mathrm{MHz}{ }^{1} \mathrm{H}$-decoupled ${ }^{13} \mathrm{C}$ NMR spectrum of 4-vinylcyclohexene oxide in 50 wt $\% \mathrm{CDCl}_{3}$ solution at $40^{\circ} \mathrm{C}$.
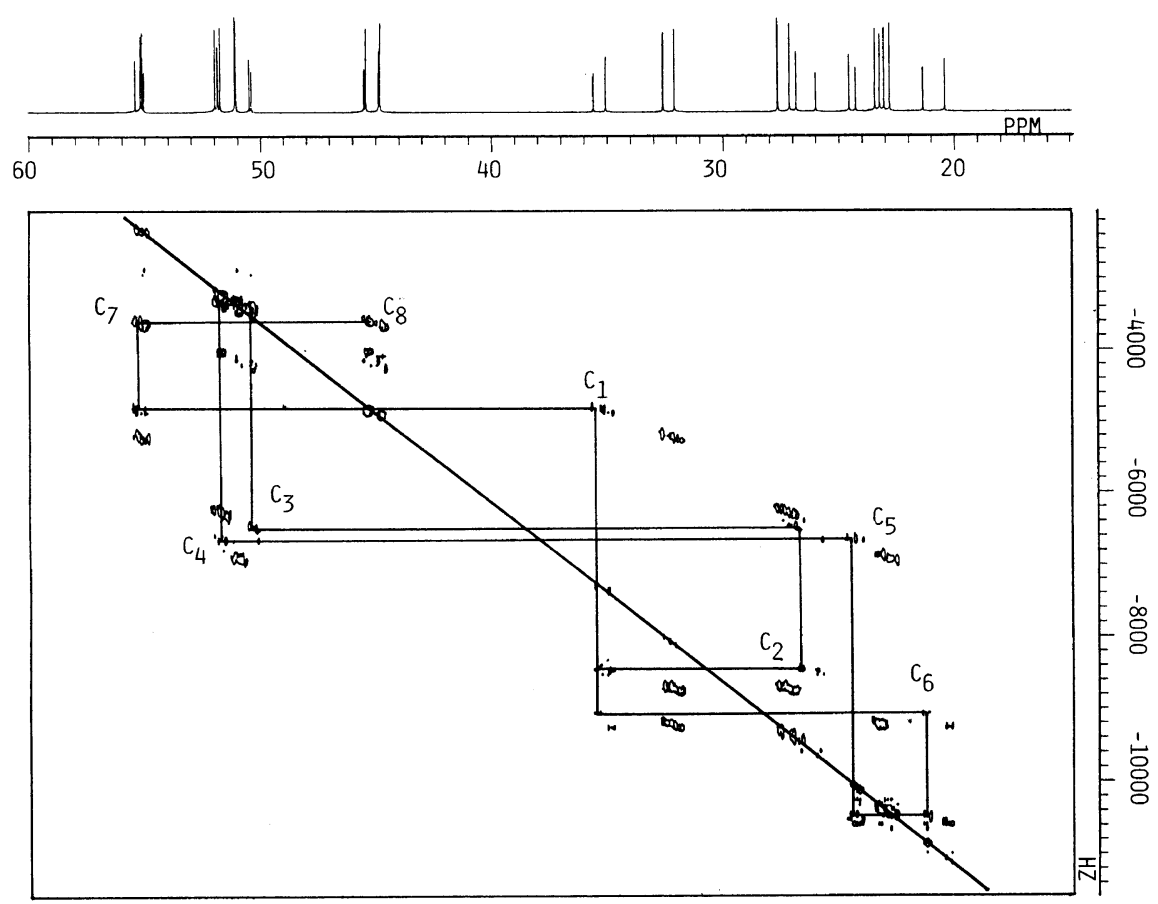

Figure 2. ${ }^{13} \mathrm{C}$ 2D INADEQUATE spectra of 4-vinylcyclohexene oxide in $50 \mathrm{wt} \% \mathrm{CDCl}_{3}$ solution at $40^{\circ} \mathrm{C}$. The ${ }^{13} \mathrm{C}-{ }^{13} \mathrm{C}$ connectivities of $\mathrm{C}_{1}-\mathrm{C}_{8}$ arising from Isomer $\mathrm{A}$ are indicated by the solid line.

shift separation is the largest) intensities of the NOE-suppressed ${ }^{13} \mathrm{C}$ NMR spectrum measured by sufficient to quantitative analysis (results not shown), and are listed in Table I.

\section{Structural Determination of VCO Isomers}

The results of the INADEQUATE analysis revealed that 4 different isomers of $\mathrm{VCO}$ are identical in their molecular skeleton. Thus the isomers should originate from the stereochemical structural difference of VCO. In Figure 3 is shown the molecular model of VCO. The ethylene oxide moiety can bond to the cyclohexane oxide ring in four dif- 


\section{A. UdaGaWA et al.}

Table I. ${ }^{13} \mathrm{C}$ NMR chemical shift assignments and isomeric composition of 4-vinylcyclohexene oxide

\begin{tabular}{cccccccccc}
\hline & \multicolumn{10}{c}{${ }^{13} \mathrm{C}$ NMR chemical shift/ppm } & Isomer \\
\cline { 2 - 9 } & $\mathrm{C}_{1}$ & $\mathrm{C}_{2}$ & $\mathrm{C}_{3}$ & $\mathrm{C}_{4}$ & $\mathrm{C}_{5}$ & $\mathrm{C}_{6}$ & $\mathrm{C}_{7}$ & $\mathrm{C}_{8}$ & Isomeric \\
composition \\
\hline $\mathrm{A}$ & 35.3 & 26.5 & 50.4 & 51.8 & 24.1 & 21.0 & 55.3 & 45.5 & 0.178 \\
$\mathrm{~B}$ & 34.7 & 25.5 & 50.2 & 51.8 & 23.8 & 19.9 & 54.9 & 44.9 & 0.212 \\
$\mathrm{C}$ & 32.2 & 27.1 & 51.9 & 51.0 & 22.6 & 23.1 & 55.1 & 45.4 & 0.293 \\
$\mathrm{D}$ & 31.6 & 26.8 & 51.6 & 51.0 & 22.3 & 22.8 & 55.0 & 44.8 & 0.317 \\
\hline
\end{tabular}

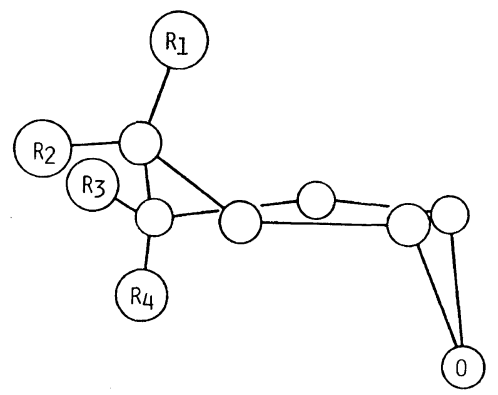

Figure 3. Molecular model of 4-vinylcyclohexene oxide. Model 1, $\mathbf{R}_{1}=\mathrm{EO}, \mathbf{R}_{2}=\mathbf{R}_{3}=\mathbf{R}_{4}=\mathbf{H} ;$ Model 2, $\mathbf{R}_{2}=\mathrm{EO}$, $\mathrm{R}_{1}=\mathrm{R}_{\mathbf{3}}=\mathrm{R}_{\mathbf{4}}=\mathrm{H}$; Model 3, $\mathrm{R}_{\mathbf{3}}=\mathrm{EO}, \mathrm{R}_{\mathbf{1}}=\mathrm{R}_{2}=\mathrm{R}_{\mathbf{4}}=\mathrm{H}$; Model $4, R_{4}=E O, R_{1}=R_{2}=R_{3}=H$, where EO is the ethylene oxide moiety.

ferent ways, i.e., at the sites of $R_{1}-R_{4}$ in the figure, creating 4 possible isomers, Models $1-4$. The ethylene oxide moiety is bonded at the axial position in Models 1 and 4 , and at the equatorial position in Models 2 and 3. The interatomic distances between $\mathrm{C}_{1}$ and oxygen of the cyclohexene oxide ring are $3.35 \AA$ in both Models 1 and 2, while $3.01 \AA$ in both Models 3 and 4 . In addition, both $\mathrm{C}_{1}$ and $\mathrm{C}_{7}$ are chiral carbons in VCO. Thus two diastereomers are possible in each model due to two configurations for $\mathrm{C}_{7}$. Therefore, a total of 8 stereochemical isomers is possible for VCO: Models $1 R, 1 S, 2 R$, $2 S, 3 R, 3 S, 4 R$, and $4 S$ ( $R$ and $S$ represent the configurations for $\mathrm{C}_{7}$ ).

The electronic structures of the 8 possible isomers should differ with each other and thus they, if present, are supposed to be identified separately in the ${ }^{13} \mathrm{C}$ NMR spectrum. The fact that only 4 independent ${ }^{13} \mathrm{C}-{ }^{13} \mathrm{C}$
Table II. Isomeric energy of 4-vinylcyclohexene oxide

\begin{tabular}{cc}
\hline Model $^{\mathrm{a}}$ & Isomeric energy $/ \mathrm{kJ} \mathrm{mol}^{-1}$ \\
\hline $1 R$ & 4.61 \\
$1 S$ & 4.13 \\
$2 R$ & 0 \\
$2 S$ & 0.30 \\
$3 R$ & 0.88 \\
$3 S$ & 1.46 \\
$4 R$ & 5.35 \\
$4 S$ & 5.64 \\
\hline
\end{tabular}

a See the text.

connectivity networks are observed in the $2 \mathrm{D}$ INADEQUATE spectrum strongly indicates that 4 isomers are realized in VCO. The ${ }^{1} \mathrm{H}^{-1} \mathrm{H}$ coupling constants are generally available for determination of such configurations. However, the ${ }^{1} \mathrm{H}$ NMR spectrum of VCO is too complicated even at a ${ }^{1} \mathrm{H}$ frequency of $500 \mathrm{MHz}$ due to severe overlapping of the signals originating from the 4 isomers, and thus could not be used in this study. Therefore the structural stability of these models was evaluated from the molecular orbital calculations to identify the molecular structures of 4 stereochemical isomers realized in VCO. The total energies of the isomeric models of VCO were calculated by the MNDO method and are listed in Table II. The models are arranged as $2 R<2 S<3 R<3 S \ll 1 S<1 R<4 R<4 S$ in the order of increasing total energy. The 4 models with the lowest energy are all in the equatorial form. There is at least a $2.67 \mathrm{~kJ}$ $\mathrm{mol}^{-1}$ difference in the energy between 
Models $3 S$ and $1 S$. Since only 4 isomers are detected in VCO, they are most likely the equatorial form, i.e., Models $2 R, 2 S, 3 R$, and $3 S$. The appearance of only the equatorial form in this epoxy resin is in agreement with the results from structural analyses on other epoxy resins which also possess cyclohexene oxide rings (ECC and EA). ${ }^{8}$ Considering both the structural stabilization energies and the isomeric composition of the 4 isomers, the stereochemical structures of Isomers A, B, C, and $\mathrm{D}$ are assigned to Models $3 S, 3 R, 2 S$, and $2 R$, respectively.

\section{CONCLUSION}

The molecular structure of the cycloaliphatic epoxy resin, 4-vinylcyclohexene oxide (VCO), was characterized by ${ }^{13} \mathrm{C}$ NMR spectroscopy and quantum chemical calculation. The ${ }^{13} \mathrm{C}$ NMR signal assignments of VCO were carried out by the 2D INADEQUATE technique. The assignments revealed the existence of 4 stereochemical isomers of VCO. The isomeric composition was 17.8:21.2: 29.3: 31.7 obtained from the signal intensity of the NOE-suppressed ${ }^{13} \mathrm{C}$ NMR spectrum. Although there are 8 possible models for the $\mathrm{VCO}$ molecule in terms of the $\mathrm{C}_{1}$ and $\mathrm{C}_{7}$ configurations, the MNDO calculations indicate that the equatorial form (Models $2 R, 2 S, 3 R$, and $3 S$ ) is considerably more stable than the axial form (Models $1 R, 1 S$, $4 R$, and $4 S$ ). Thus the former should be the isomers in the ${ }^{13} \mathrm{C}$ NMR spectrum of VCO. In addition, analyses on the isomeric energy of the VCO diastereomers further lead to the complete structural determination of each VCO isomer. Isomers $\mathrm{A}, \mathrm{B}, \mathrm{C}$, and $\mathrm{D}$ were found identical to Models $3 S, 3 R, 2 S$, and
$2 R$, respectively.

Acknowledgements. The authors wish to thank Dr. Minoru Sakurai, Tokyo Institute of Technology for his helpful discussion on the MNDO calculations. One (A.U.) of them thanks Sumitomo 3M Limited for his leave from the company to conduct this study at Tokyo Institute of Technology.

\section{REFERENCES}

1. W. W. Fleming, J. Appl. Polym. Sci., 30, 2853 (1985).

2. S. A. Sojka and W. B. Moniz, J. Appl. Polym. Sci., 20, 1977 (1976)

3. C. F. Poranski, W. B. Moniz, D. L. Birkle, J. T. Kopfle, and S. A. Sojka, NRL Report, June 22, 1977, p 8092.

4. M. F. Grenier-Loustalot and P. Grenier, J. Polym. Sci., Polym. Chem. Ed., 22, 4011 (1984).

5. F. G. Herring and N. R. Jagannathan, J. Polym. Sci., Polym. Chem. Ed., 23, 1649 (1985).

6. N. R. Jagannathan and F. G. Herring, Polymer, 27, 1493 (1986).

7. N. R. Jagannathan and F. G. Herring, J. Polym. Sci., A, Polym. Chem., 25, 897 (1987).

8. A. Udagawa, Y. Yamamoto, and R. Chûjô, Polymer (in press).

9. B. Ottar, Acta Chem. Scand., 1, 283 (1947).

10. A. Bax, R. Freeman, and S. P. Kempsell, J. Am. Chem. Soc., 102, 4851 (1980).

11. A. Bax, R. Freeman, and T. Frenkiel, J. Am. Chem. Soc., 103, 2102 (1981).

12. R. Freeman and T. Frenkiel, J. Am. Chem. Soc., 104, 5545 (1982).

13. G. Bodenhausen, H. Kogler, and R. R. Ernst, J. Magn. Reson., 58, 370 (1984).

14. T. Hayashi, Y. Inoue, R. Chûjô, and T. Asakura, Polym. J., 20, 895 (1988).

15. M. J. S. Dewar and W. Thiel, J. Am. Chem. Soc., 99, 4899 (1977).

16. W. Thiel, J. Am. Chem. Soc., 103, 1413 (1981).

17. R. E. Parker and N. S. Isaacs, Chem. Rev., 59, 737 (1959). 